\title{
HPTLC coupled to ESI-Tandem MS for identifying phospholipids associated to membrane proteins in photosynthetic purple bacteria
}

María P. Lapieza, Colette Jungas, María Savirón, Carmen Jarne, Luis Membrado, Jesús Vela, Jesús Orduna, Rosa Garriga, Javier Galbán \& Vicente L. Cebolla

To cite this article: María P. Lapieza, Colette Jungas, María Savirón, Carmen Jarne, Luis Membrado, Jesús Vela, Jesús Orduna, Rosa Garriga, Javier Galbán \& Vicente L. Cebolla (2019) HPTLC coupled to ESI-Tandem MS for identifying phospholipids associated to membrane proteins in photosynthetic purple bacteria, Journal of Liquid Chromatography \& Related Technologies, 42:1-2, 1-8, DOI: $10.1080 / 10826076.2018 .1561465$

To link to this article: https://doi.org/10.1080/10826076.2018.1561465

曲 Published online: 04 Mar 2019.

Submit your article to this journal $₫$

Џ Article views: 45

View Crossmark data $₫$ 


\title{
HPTLC coupled to ESI-Tandem MS for identifying phospholipids associated to membrane proteins in photosynthetic purple bacteria
}

\author{
María P. Lapieza ${ }^{a}$, Colette Jungas ${ }^{b}$, María Savirón $^{c}$, Carmen Jarne ${ }^{a}$, Luis Membrado ${ }^{a}$, Jesús Vela ${ }^{d}$, Jesús Orduna ${ }^{c}$, \\ Rosa Garriga ${ }^{e}$, Javier Galbán ${ }^{d}$, and Vicente L. Cebolla ${ }^{a}$

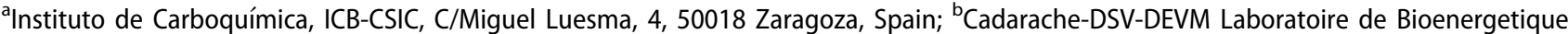

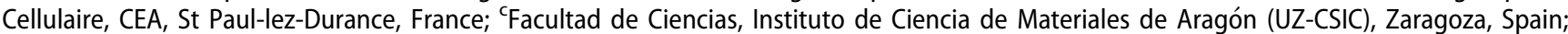 \\ Departamento de Química Analítica, Facultad de Ciencias, Universidad de Zaragoza, Zaragoza, Spain; ${ }^{e}$ Departamento de Química Física, \\ Facultad de Ciencias, Universidad de Zaragoza, Zaragoza, Spain
}

\begin{abstract}
High-performance thin-layer chromatography (HPTLC)-densitometry was directly combined with electrospray (ESI) tandem mass spectrometry for obtaining rapid and relevant structural identification of phospholipids (PL) species associated to membrane proteins (MP), in non-sulfur, purple bacteria having photosynthetic activity. Thus, species belonging to phosphatidylcholines (PC), phosphatidylethanolamines (PE), cardiolipins $(\mathrm{CL})$ and phosphatidylglycerols $(\mathrm{PG})$ associated to MP were investigated in bacterial membrane extracts from Rhodobacter (Rb.) blasticus, Rhodospirillum (R.) rubrum and Rhodobaca (Rbc.) bogoriensis, as well as those which are bound to a purified MPphotosynthetic complex from Rbc. bogoriensis.

PL-classes were separated using a 7-step gradient-solvent sequence with a previous acid plate preconditioning, using Automated Multiple Development. Band zones of the plate corresponding to PL classes were selected to ensure their direct transfer to ion-trap MS equipment through an elution-based interface.

Under the studied conditions, $\mathrm{ESI}^{+}-\mathrm{MS}$ spectra of $\mathrm{PC}$ and $\mathrm{CL}$ mostly showed sodium adducts $\left([\mathrm{M}+\mathrm{Na}]^{+}\right)$and $[\mathrm{M}-2 \mathrm{H}+3 \mathrm{Na}]^{+}$, respectively, when recorded from the plate. The respective sodium adducts were fragmented in the ion-trap, and sodium remained as the charge of the fragment ions, thus being useful for their structural identification through MS/MS. ESI'-MS and MS/MS spectra of $\mathrm{CL}$ were also obtained as $[\mathrm{M}-2 \mathrm{H}]^{2-}$, as well as those of PE and PG species as $[\mathrm{M}-\mathrm{H}]^{-}$and $[\mathrm{M}]^{-}$, respectively.

In this way, relative composition profiles of each studied PL-class by ESI-MS, and further identification of individual PL and the molecular species belonging to each of them by MS/MS were obtained.

Graphical Abstract
\end{abstract}

\section{GRAPHICAL ABSTRACT}

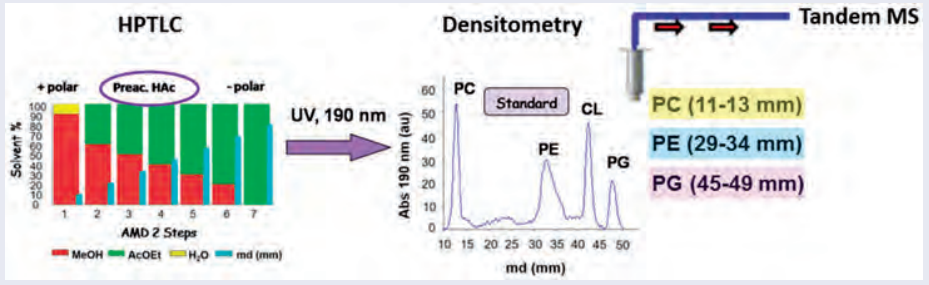

\section{ARTICLE HISTORY}

Received 11 December 2018 Accepted 18 December 2018

\section{KEYWORDS}

HPTLC-MS; phospholipids; Electrospray mass spectrometry; phospholipids identification

\section{Introduction}

Electrospray (ESI) is a soft ionization technique, hardly destructive, which allows the observation of intact molecules with one or multiple, positive or negative charges. Molecular ions and even adducts, and other weakly bound-complexes in solution can be detected as aggregates or non-covalent complexes. Thus, we speak of minimal in-source fragmentation [1].
The use of an elution-based interface to directly coupling HPTLC with ESI-MS equipments has become popular and has been applied to a wide number of analytes, including lipids $[2,3]$. Using this interface, a modular, simple, rapid and direct transfer of separated HPTLC bands can be achieved in the desired zones of the plate, owing to: the open HPTLC configuration; the post-chromatographic removal of the mobile phase before extraction by the 
interface solvent; and the previous detection of the relevant chromatographic zones by densitometry.

Although ions obtained in HPTLC-ESI-MS spectra may provide a structural pre-identification of the lipid species, unambiguous identification is not possible if it is not confirmed by MS/MS or High-Resolution MS (HRMS).

However, obtaining MS/MS spectra by tandem techniques directly from the chromatographic plate has been a very little used resource so far. Recording of MS/MS spectra of lipids had been hampered by the ubiquitous presence of sodium ions during the chromatographic process, and their coexistence with protonated ions. This causes a poor fragmentation of the isolated precursor ions, which complicates or prevents the structural interpretation of the product ions.

In a previous work, we demonstrated that it is possible to obtain HPTLC-ESI-MS working conditions so that the sodium adducts from a wide variety of lipids can be fragmented in positive ESI mode $\left(\mathrm{ESI}^{+}\right)$, directly from the plate [4]. This has been useful for unequivocal structural identification of lipid species from different classes in complex samples by $\mathrm{ESI}^{+}$-MS/MS, such as: mono- and di-acylglycerides in a fatty acid methyl ester (FAME)-based biodiesel sample, as low-concentration impurities. Likewise, molecular species of sphingomyelins and globotriaosylceramides were unequivocally identified in human plasma samples. As well, analytical conditions were compatible with ionization in negative mode $\left(\mathrm{ESI}^{-}\right)$for lipid classes that did not show an adequate ionization in positive mode (e.g. fatty acids). In some of these cases, Ion-trap MS allowed the additional possibility of multi-stage tandem analysis $\left(\mathrm{MS}^{\mathrm{n}}\right)$ since it is possible to perform successive isolations and fractionation of product ions. This was of interest for determining fragmentation pathways of different sphingolipids in human plasma analysis.

Our present work intends to evaluate whether phospholipids (PL) from complex samples may also be identified using HPTLC-tandem MS. Our aim is the identification of molecular species from different PL classes which are associated to membrane proteins (MP) in photosynthetic non-sulfur purple bacteria.

Embedded in the lipid bilayer, membrane proteins (MP) cannot be removed without disrupting the cellular membrane. In this process, PL is closely associated to these proteins [5]. Isolation of MP is done by extraction using special detergents. The behavior of MP in further purification and characterization steps will depend on the mixed micelles containing lipid, protein, and detergent formed during the extraction process. Usually, the use of excessive amounts of detergents prevents MP crystallization or the high-resolution diffraction of the crystals obtained, and may even produce their inactivation [6].

PL surrounding MP was also classically considered as a nuisance that had to be removed to obtain purified MP. However, it is now known that PL associated to MPs in biological membranes play an important role in the activity of these proteins, directly influencing their stability [7]. Therefore, PL removal may lead to the loss of biological activity of MP. Likewise, PL modifies the compactness of the Protein-Detergent-Lipid complex and to change the shape and resolution of MP-crystals, favouring crystallization [6]. For these reasons, it is of great interest to identify PL structures associated to MP.

The information provided by high-resolution structures obtained from X-ray diffraction of crystallized MP and computer simulations has been very useful to study possible configurations of membrane lipids. However, as M. Luckey points out [5], lipids observed in static crystals of membrane proteins may be very dissimilar from the lipids in native membranes mostly for two reasons. In addition to the fact that a substantial part of the native lipids is lost after the successive stages of purification of the MP for crystallization, the addition of non-native lipids is often also used to enhance the crystallization of the MP in the detergent.

In this context, the use of HPTLC-MS to study native PL present in both direct membrane extracts and more directly associated or bound to MP, is of interest.

We are interested in MP involved in the photosynthetic activity of non-sulfur purple bacteria [8]. In these, the RCLH1-pufX complex is usually presented as a dimer [9-11]. The primary reactions of photosynthesis are carried out by an RC-LH1 complex formed by the photochemical reaction center (RC) and the LH1 light-harvesting pigment-protein. Complete structural closure of the RC by the LH1 is prevented by the association of a small protein, pufX.

Indeed, the primary reactions of anoxygenic photosynthesis are carried out by an RC-LH1 complex formed by the photochemical reaction center (RC) and the LH1 light-harvesting pigment-protein. In the Rb. blasticus and Rbc. bogoriensis membranes the RC-LH1-pufX complexes are present as dimers and LH1 antenna do not form closed rings around the RCs, but do form an open " $\mathrm{C}$ " (hence an " $\mathrm{S}$ " shape for the dimer) [9-11]. Complete structural closure of the RC by the LH1 is prevented by the association of a small protein, pufX.

Therefore our aim is to identify, by HPTLC-MS, molecular species from different PL classes, which are associated to MP in several bacterial membrane extracts (Rhodobacter $(R b$.) blasticus, Rhodospirillum (R.) rubrum and Rhodobaca (Rbc.) bogoriensis, and in a purified MP-photosynthetic complex (RC-LH1-pufX) of one of these bacteria (Rbc. bogoriensis). The following PL classes were explored: PC (phosphatidylcholines), PG (phosphatidylglycerols), PE (phosphatidylethanolamines) and CL (cardiolipins). Standards of these classes were used to select the appropriate ESI ionization mode and evaluate ionization/fragmentation patterns on silica gel plates with regard to those obtained in solution.

\section{Experimental}

\subsection{Standards and samples}

The following standards were used, which corresponded to the searched PL classes (phophatidylcholines PC, phosphatidylethanolamines PE, phosphatidylglycerols PG, and cardiolipins CL). They were purchased from Sigma-Aldrich (Madrid, Spain): PC standard: 1,2-diacyl-sn-glycero-3-phosphocholine, CAS [8002-43-5], from egg yolk ( $\geq 99 \%)$; PE 
standard: 1,2-diacyl-sn-glycero-3-phosphoethanolamine, CAS [39382-08-6], from egg yolk ( $\geq 97 \%)$; PG standard: 1,2diacyl-sn-glycero-3-phospho-(1-rac-glycerol), CAS [8014686-7], from egg yolk lecithin, ( $\geq 99 \%)$; CL standard: diphosphatidylglycerol, CAS [64043-42-1], from bovine heart, $(\geq 97 \%)$.

For a given PL class, the notation adopted for the identity of a molecular species was $(x: y)$ where $x$ is the carbon number of the fatty acid-chains of the molecule; and $y$ corresponds to the total number of double bonds.

Photosynthetic membrane was extracted from $R b$. blasticus, $R d$. rubrum and $R b c$. bogoriensis bacteria. The purified RC-LH1-PufX complexes isolated from Rbc. bogoriensis were prepared using the method reported by Comayras et al. [10], and by Semchonok et al. [11].

\subsubsection{Isolation of photosynthetic membranes}

Briefly, freshly harvested cells were collected by low speed centrifugation at $8000 \times g$, washed with $50 \mathrm{~mm}$ Tris- $\mathrm{HCl}$ $(\mathrm{pH} 8)$, and subjected to three cycles with French press at 16,000 p.s.i. The resulting unbroken cells and debris were removed by centrifugation at $20,000 \times g$ for $30 \mathrm{~min}$ at $4{ }^{\circ} \mathrm{C}$. The photosynthetic membranes were then pelleted at $200,000 \times g$ for $90 \mathrm{~min}$ and re-suspended in $50 \mathrm{~mm}$ Tris- $\mathrm{HCl}$ (pH 8).

\subsubsection{Isolation and purification of the photosynthetic RC- LH1-PufX complex}

The photosynthetic membranes were solubilized with $1 \%$ $\beta$-dodecyl maltoside (Calbiochem) for $10 \mathrm{~min}$ at $4{ }^{\circ} \mathrm{C}$ and then ultracentrifuged at $200,000 \times g$ for $30 \mathrm{~min}$ to remove the insoluble material. The solubilized complexes were laid on a continuous density sucrose gradient containing $50 \mathrm{~mm}$ Tris- $\mathrm{HCl}(\mathrm{pH} 8), 0-1 \mathrm{M}$ sucrose, and $0.03 \% \beta$-dodecyl maltoside and ultracentrifuged at $200,000 \times g$ for $15 \mathrm{~h}$ at $4{ }^{\circ} \mathrm{C}$. The dimeric RC-LH1-pufX complexes were carefully removed using a syringe. To eliminate some contamination, they were applied to a Mono $\mathrm{Q}$ anion exchange fast protein liquid chromatography column (Amersham Biosciences) pre-equilibrated with $50 \mathrm{mM}$ Tris- $\mathrm{HCl}(\mathrm{pH} 8)$, and $0.03 \%$ $\beta$-dodecyl maltoside. After washing with $5 \mathrm{ml}$ of buffer, the complexes were eluted with a $30-\mathrm{mL}$ linear gradient of $0-500 \mathrm{mM} \mathrm{NaCl}$ at a rate of $0.5 \mathrm{~mL} / \mathrm{min}$.

\subsubsection{Phospholipid extraction and HPTLC sample application}

Lipid extraction was performed from $800 \mu \mathrm{L}$ of the previously isolated RC-LH1-PufX complex $\left(1-1.5 \mathrm{mg} \mathrm{mL}^{-1}\right)$ or $100 \mu \mathrm{L}$ of membranes $\left(10 \mathrm{mg} \mathrm{mL}^{-1}\right)$, diluted with $700 \mu \mathrm{L}$ of water. $\mathrm{CHCl}_{3}-\mathrm{MeOH}(1: 1, \mathrm{v} / \mathrm{v}, 3 \mathrm{~mL})$ was added to tubes previously rinsed in $\mathrm{CHCl}_{3}$. All glass material was also rinsed in $\mathrm{CHCl}_{3}$ to remove traces of fatty acids. The tube was vortexed for $10 \mathrm{~min}$. In addition, $1 \mathrm{~mL}$ of $\mathrm{CHCl}_{3}$ (vortex $30 \mathrm{~s}$ ) and $1 \mathrm{~mL}$ of $0.9 \% \mathrm{NaCl}$ were added. The tubes were shaken for $10 \mathrm{~min}$ and then centrifuged $\left(5 \mathrm{~min}, 4 \times 10^{3} \mathrm{rpm}\right.$, $4{ }^{\circ} \mathrm{C}$ ). The organic phase (lower) was recovered. The aqueous phase was extracted again twice with $1 \mathrm{~mL}$ of $\mathrm{CHCl}_{3}$. After gathering the organic phases, they were evaporated under $\mathrm{N}_{2}$ flow. The lipids were then re-dissolved in a volume between 650 and $850 \mu \mathrm{L}$ of DCM-MeOH $(1: 1, \mathrm{v} / \mathrm{v})$.

Standards $(2.0 \mu \mathrm{g} / \mathrm{band})$ and samples $(5.0 \mu \mathrm{L} / \mathrm{band})$ were applied in duplicate on a $20 \times 10 \mathrm{~cm}$-HPTLC silica gel plate using an automated ATS4 system (CAMAG, Müttenz, Switzerland), as $4 \mathrm{~mm}$-bands.

\subsection{AMD - Videodensitometry of phospholipid classes}

Conditions using Automated Multiple Development (AMD2 system from CAMAG, Muttenz, Switzerland) were selected to provide PL-classes (PC, PE, CL, PG) as separated bands from the migration distances ( $\mathrm{md}$, in $\mathrm{mm}$ ) of PL standards. A 7-step gradient based on $\mathrm{MeOH}-\mathrm{H}_{2} \mathrm{O}$-AcOEt (Table 1) was selected, with a previous plate preconditioning using acetic acid (HAc) $1 \mathrm{~N}$ (Figure 1(a)). Arrangement of samples on the plate is detailed in Figure 1(b). Bands were detected by UV densitometry $(190 \mathrm{~nm})$ and videodensitometry $(366 \mathrm{~nm})$ using a TLC Scanner 3 (CAMAG).

\subsection{HPTLC-MS}

The respective interest zones selected for each PL-class was: PC (11-13 mm), PE (29-34 mm), CL (39-41 mm), and PG $(45-49 \mathrm{~mm})$. They were directly extracted, eluted and transferred to an ESI-ion trap MS (Esquire 3000 Plus system, Bruker Daltonics, Bremen, Germany) using the elutionbased TLC-MS interface 2 (CAMAG). The operating scheme of the interface was described and depicted elsewhere [4].

Settings for the full scan $(m / z 50-1500)$ in the positive $\left(\mathrm{ESI}^{+}\right)$or negative $\left(\mathrm{ESI}^{-}\right)$mode were $-1+4000 \mathrm{~V}$ as capillary voltage, $-/+500 \mathrm{~V}$ as end plate voltage, $40 \mathrm{psi}$ as pressure of the nebulizer gas $\left(\mathrm{N}_{2}\right), 9.0 \mathrm{~L} / \mathrm{min}$ as flow rate of the drying gas $\left(\mathrm{N}_{2}\right)$ and $350{ }^{\circ} \mathrm{C}$ as drying gas temperature. Bruker Daltonics Esquire Control software packages v.5.3, and Data Analysis v.4.0 were used to control the mass spectrometer and process data. For lipid identification, LIPID MAPS software was used (http://www.lipidmaps.org).

For spectra interpretation, formation of sodiated background clusters $\left[\mathrm{Na}^{+}\left(\mathrm{CH}_{3}-\mathrm{COONa}\right)_{\mathrm{n} 1},(\mathrm{HCOONa})_{\mathrm{n} 2},(\mathrm{n} 1\right.$, $\mathrm{n} 2 \geq 0$ ), with $\mathrm{m} / \mathrm{z} \Delta=82$ for sodium acetate, and $\mathrm{m} / \mathrm{z}$ $\Delta=68$ for sodium formiate], and sample ion clusters $[\mathrm{M}+\mathrm{Na}]^{+}\left(\mathrm{CH}_{3}-\mathrm{COONa}\right) /[\mathrm{M}+\mathrm{Na}]^{+}(\mathrm{HCOONa})$, were considered as artifacts $[12,13]$.

High Resolution (HR)-MS of CL standard in a methanol solution was done using a ESI-micro time of flight

Table 1. AMD conditions for separating phospholipid classes in bacterial membrane sample.

\begin{tabular}{lcccc}
\hline $\begin{array}{l}\text { Chromatographic } \\
\text { step }\end{array}$ & $\begin{array}{c}\mathrm{MeOH} \\
(\mathrm{v} / \mathrm{v}, \%)\end{array}$ & $\begin{array}{c}\mathrm{AcOEt} \\
(\mathrm{v} / \mathrm{v}, \%)\end{array}$ & $\begin{array}{c}\mathrm{H}_{2} \mathrm{O} \\
(\mathrm{v} / \mathrm{v}, \%)\end{array}$ & $\begin{array}{c}\text { Migration } \\
\text { distance }(\mathrm{mm})\end{array}$ \\
\hline 1 & 90 & 0 & 10 & 10.0 \\
2 & 60 & 40 & 0 & 21.6 \\
3 & 50 & 50 & 0 & 33.2 \\
4 & 40 & 60 & 0 & 44.8 \\
5 & 30 & 70 & 0 & 56.4 \\
6 & 20 & 80 & 0 & 68.0 \\
7 & 0 & 100 & 0 & 79.6 \\
\hline
\end{tabular}



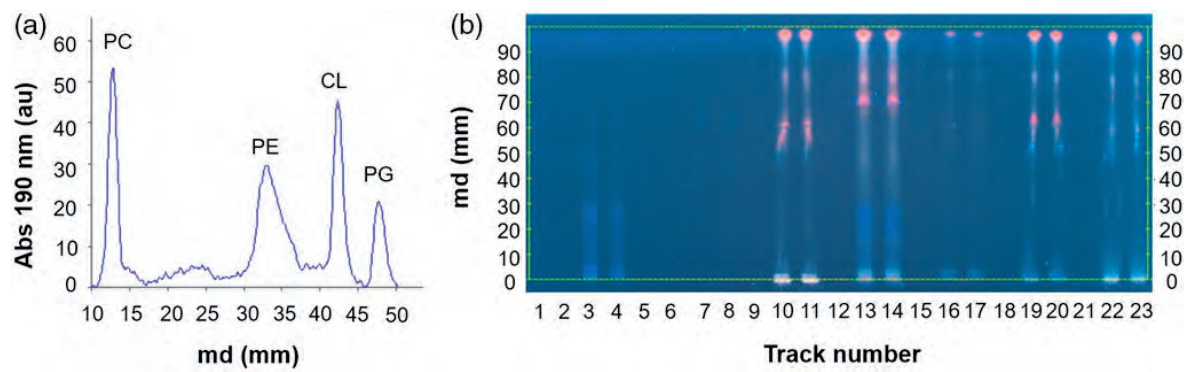

Figure 1. (a) HPTLC-densitometry (UV, $190 \mathrm{~nm}$ ) of PC, PE, CL and PG standards ( $2 \mu \mathrm{g} / \mathrm{band}$ ). AMD conditions in Table 1. (b) Videodensitometry (UV, $366 \mathrm{~nm}$ ) of PC standard (tracks 1,2; $2 \mu \mathrm{g} / \mathrm{band}) ; \mathrm{PE}(3,4 ; 2 \mu \mathrm{g} / \mathrm{band}) ; \mathrm{CL}(5,6 ; 2 \mu \mathrm{g} / \mathrm{band}) ; \mathrm{PG}(7,8 ; 2 \mu \mathrm{g} /$ band); blank track (9); Rb. blasticus extract $(10,11 ; 5 \mu \mathrm{L} / \mathrm{band}) ;$ blank track (12); $R d$. rubrum extract $(13,14 ; 5 \mu \mathrm{L} /$ band); blank track (15); Rbc. bogoriensis extract (16,17,19,20; $5 \mu \mathrm{L} /$ band); blank track (18); blank track (21), RC-LH1-PufX complex from $R b c$. bogoriensis $(22,23 ; 5 \mu \mathrm{L} /$ band).

quadrupole-mass spectrometer (micro-QTOF; Bruker Daltonics, Bremen, Germany) and micro-QTOF Control version 2.3 software.

\section{Results and discussion}

Selected gradient AMD and densitometry conditions allow an adequate separation of PL classes; provides a sodiated medium for $\mathrm{ESI}^{+}$; and favours band localization for an adequate coupling with MS via the elution-based interface. Each selected band can be directly transferred in seconds to an ion-trap mass spectrometer.

The corresponding plate zones were punched out in the samples using a $2 \times 4 \mathrm{~mm}$-oval head interface, taking into account the corresponding migration distances (md) of PL standards. However, as a matrix effect was noticed, an inspection of the elution limits of each PL class zone was performed for the samples.

\subsection{Phospholipid standards}

The standards used, coming from natural sources, were analytical problems in themselves since their commercial specifications did not detail their composition in fatty acids. Thus, their phospholipid species were identified ( Figures $2-5)$ as were the problem samples, using the HPTLC-densitometry-MS conditions described in the present work.

$\mathrm{ESI}^{+}$-MS spectrum of the PC standard showed sodium adducts $\left[\mathrm{C}_{42} \mathrm{H}_{82} \mathrm{O}_{8} \mathrm{PN}+\mathrm{Na}\right]^{+}$at $\mathrm{m} / \mathrm{z} \quad 782.7$, and $\left[\mathrm{C}_{44} \mathrm{H}_{86} \mathrm{O}_{8} \mathrm{PN}+\mathrm{Na}\right]^{+}$at $\mathrm{m} / \mathrm{z} 810.7$ when obtained from the silica gel plate (Figure 2(a)) which were assigned to a mixture of PC (34:1), most abundant, and PC (36:1). HPTLC$\mathrm{ESI}^{+}$-MS/MS confirmed these assignments. As an example (Figure 2(b)), the precursor ion at $\mathrm{m} / \mathrm{z} 782.7$ was isolated and fragmented. The corresponding MS/MS spectrum displayed ion products at $\mathrm{m} / \mathrm{z} 723.2$ and predominantly 599.3, which corresponded to the loss of trimethylamine $\left[-\mathrm{N}\left(\mathrm{CH}_{3}\right)_{3}\right]$ and phosphocholine $\left[-\left(\mathrm{CH}_{2}\right) \mathrm{PO}_{4} \mathrm{~N}\left(\mathrm{CH}_{3}\right)_{3}\right]$ groups, respectively. As shown in this figure, the sodium remained as charge of the fragments after tandem fragmentation. This allows for unequivocal structural identifications through the product ions (MS/MS).

PG and PE standards were ionized by ESI in negative mode, as $[\mathrm{M}]^{-}$and $[\mathrm{M}-\mathrm{H}]^{-}$, respectively. Figure 3 shows that the PG standard spectrum presents a most abundant
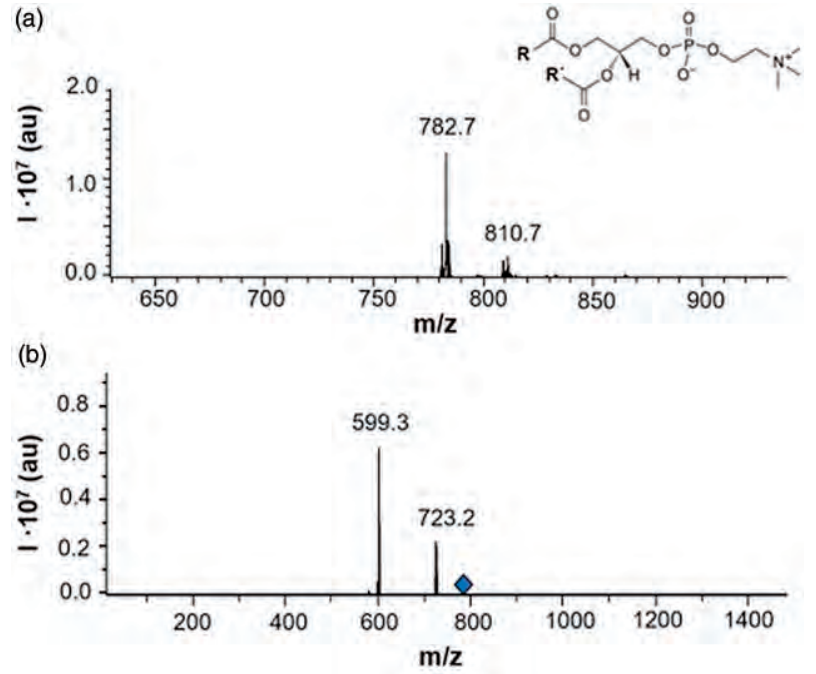

Figure 2. (a) HPTLC-ESI ${ }^{+}-\mathrm{MS}$ spectrum of PC standard (inset: molecular structure of PC). (b) HPTLC-ESI ${ }^{+}-M S / M S$ spectrum of the precursor ion at $\mathrm{m} / \mathrm{z} 782.7$ with product ions at $\mathrm{m} / \mathrm{z} 723.2 ; 599.3$. (See text for ion attribution).

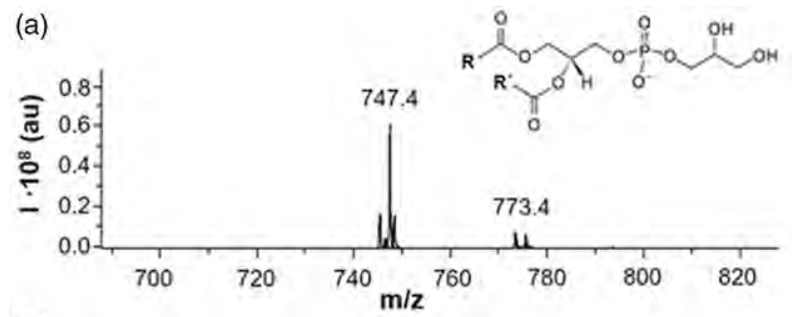

(b)
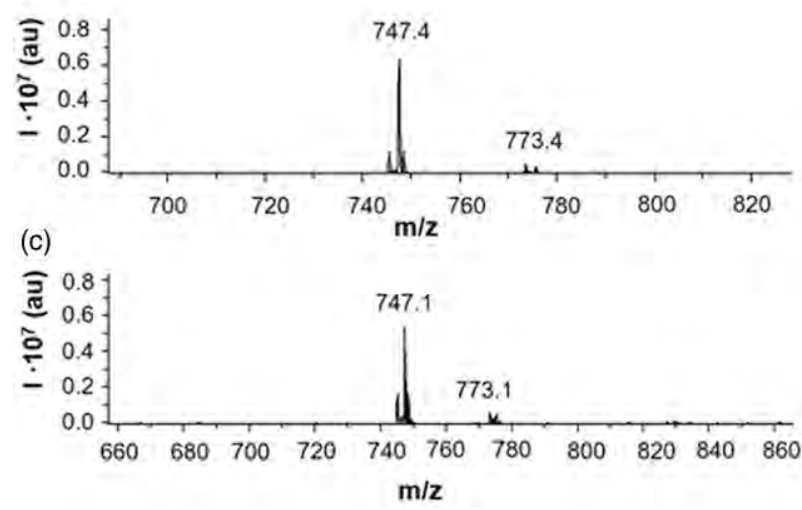

Figure 3. (a) $\mathrm{ESI}^{-}-\mathrm{MS}$ spectrum of a methanol solution of PG standard, recorded at $t=0$ (days). (b) HPTLC-ESI ${ }^{-}$-MS spectrum of PG standard, recorded at $t=0$ (days). (c) HPTLC-ESI ${ }^{-}$-MS of PG standard, recorded at $t=120$ (days). (Inset: molecular structure of PG). (See text for ion attribution). 
ion $\left[\mathrm{C}_{40} \mathrm{H}_{76} \mathrm{O}_{10} \mathrm{P}\right]^{-}$at $\mathrm{m} / \mathrm{z} 747.4$ which corresponds to PG (34:1), and another less abundant one $\left[\mathrm{C}_{42} \mathrm{H}_{78} \mathrm{O}_{10} \mathrm{P}\right]^{-}$at $\mathrm{m} / \mathrm{z}$ 773.4 which corresponds to $\mathrm{PG}$ (36:2). This figure shows that the spectra obtained from the plate are practically identical and have similar intensity to those obtained in solution. Likewise, they are also stable over time.

Bearing four chains of fatty acids and two phosphate groups in their structure, CL can also be ionized either by $\mathrm{ESI}^{-}$as $[\mathrm{M}-2 \mathrm{H}]^{2-}[14]$ (Figure 4 ), or by $\mathrm{ESI}^{+}$as $[\mathrm{M}-$ $2 \mathrm{H}+3 \mathrm{Na}]^{+}[15]$ (Figure 5).

In the first case, $\left[\mathrm{C}_{81} \mathrm{H}_{142} \mathrm{O}_{17} \mathrm{P}_{2}-2 \mathrm{H}\right]^{2-}$ at $\mathrm{m} / \mathrm{z} 723.4$ corresponds mostly to CL (72:8) (Figure 4(a)). Confirmation of this assignation was done by isolating and fragmenting this di-anion to obtain its MS/MS spectrum (Figure 4(b)). The corresponding product ion at $\mathrm{m} / \mathrm{z} 592.1$ can be attributed to $[\mathrm{M}-2 \mathrm{H}-\mathrm{RC}=\mathrm{O}=\mathrm{O}]^{2-}$, which is in agreement to the product ion found by Alves Maciel [16], which was obtained from a solution of CL standard. In our case, spectra from the HPTLC plate are practically identical to those obtained in solution.

As in the case of the other studied standards, phospholipids are not oxidized on the plate in any case under our working conditions. In the case of a forced ambient oxidation of CL, ions in the ESI-MS ${ }^{-}$spectrum from the plate are also exactly the same than those obtained from a CL solution, which were reported elsewhere by Maciel et al. [17]. Thus, ion at $\mathrm{m} / \mathrm{z} 723.5$ corresponds to $\left[\mathrm{C}_{81} \mathrm{H}_{142} \mathrm{O}_{17} \mathrm{P}_{2}-2 \mathrm{H}\right]^{2-}$, i.e. $\mathrm{CL}(72: 8)$; ions at $\mathrm{m} / \mathrm{z} 279.1,415.1,592.3$, and 1167.7 corresponds, respectively, at structures $[\mathrm{RCOO}]^{-},[\mathrm{PA}-\mathrm{RCOOH}-$ $\mathrm{H}]^{-},[\mathrm{M}-2 \mathrm{H}-\mathrm{R}=\mathrm{C}=\mathrm{O}]^{2-}$, and $[\mathrm{M}-2 \mathrm{H}-\mathrm{RCOO}]^{-}$, where $\mathrm{PA}$ is phosphatidic acid (see Figure 4(c)).

Concerning $\mathrm{ESI}^{+}$, Figure 5 displays the spectrum of a solution of CL standard in methanol (A) and that obtained from the silica gel plate (B). ESI-MS spectrum in solution shows the complexity of CL standard. Ions at $\mathrm{m} / \mathrm{z} 1516.9139$ and 769.4614 were identified by High-Resolution QTOF-MS and can be attributed to $\mathrm{CL}(72: 8)$, as $\left[\mathrm{C}_{81} \mathrm{H}_{142} \mathrm{O}_{17} \mathrm{P}_{2^{-}}\right.$ $2 \mathrm{H}+3 \mathrm{Na}]^{+}$and $\left[\mathrm{C}_{81} \mathrm{H}_{142} \mathrm{O}_{17} \mathrm{P}_{2}-2 \mathrm{H}+4 \mathrm{Na}\right]^{2+}$, respectively, with theoretical signals at $\mathrm{m} / \mathrm{z} 1515.9253$ (deviation 12.4 $\mathrm{mDa}$ or $8.2 \mathrm{ppm}$ ) and $\mathrm{m} / \mathrm{z} 769.4573$ (deviation $4.1 \mathrm{mDa}$ or $5.4 \mathrm{ppm}$ ). Other probable structures found in CL standard were $\mathrm{CL}(60: 8)$, and $\mathrm{CL}(40: 8)$ (Figure 5(b)). The corresponding spectrum of CL standard obtained from the plate basically showed ions at the same $\mathrm{m} / \mathrm{z}$ than those obtained in solution. Thus, ions at $\mathrm{m} / \mathrm{z} \quad 1515.7 \quad\left[\mathrm{C}_{81} \mathrm{H}_{142} \mathrm{O}_{17} \mathrm{P}_{2^{-}}\right.$ $2 \mathrm{H}+3 \mathrm{Na}]^{+}, 1347.7\left[\mathrm{C}_{69} \mathrm{H}_{118} \mathrm{O}_{17} \mathrm{P}_{2}-2 \mathrm{H}+3 \mathrm{Na}\right]^{+}$, and 1075.6 $\left[\mathrm{C}_{49} \mathrm{H}_{86} \mathrm{O}_{17} \mathrm{P}_{2}-2 \mathrm{H}+3 \mathrm{Na}\right]^{+}$may be attributed to $\mathrm{CL}(72: 8)$, $\mathrm{CL}(60: 8)$ and $\mathrm{CL}(40: 8)$, respectively.

\subsection{Membrane extracts from Rhodobacter (Rb.) blasticus and Rhodospirillum (R.) rubrum}

In HPTLC-ESI-MS spectrum of each PL-class, relative ion intensities of molecular species may be related to their concentration.

It has long been known that ESI ionization efficiencies are similar for molecular species belonging to a given class of lipids [1]. It is the polar groups of lipids that define the
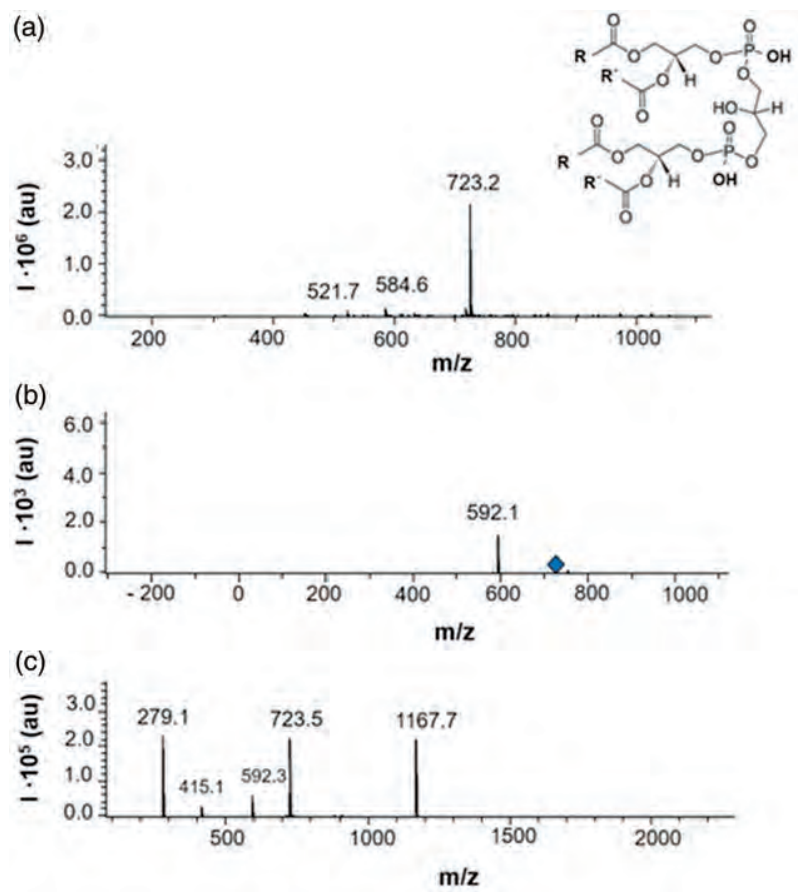

Figure 4. (a) HPTLC-ESI-MS spectrum of $\mathrm{CL}$ standard. (b) HPTLC-ESI-MS/MS spectrum of the precursor ion at $\mathrm{m} / \mathrm{z} 723.2$, with detail of product ion at $\mathrm{m} / \mathrm{z}$ 592.1. (See text for ion attribution). (c) ESI-MS spectrum corresponding to the products coming from a forced oxidation of $\mathrm{CL}$ standard, in a methanol solution. (See text for ion attribution).
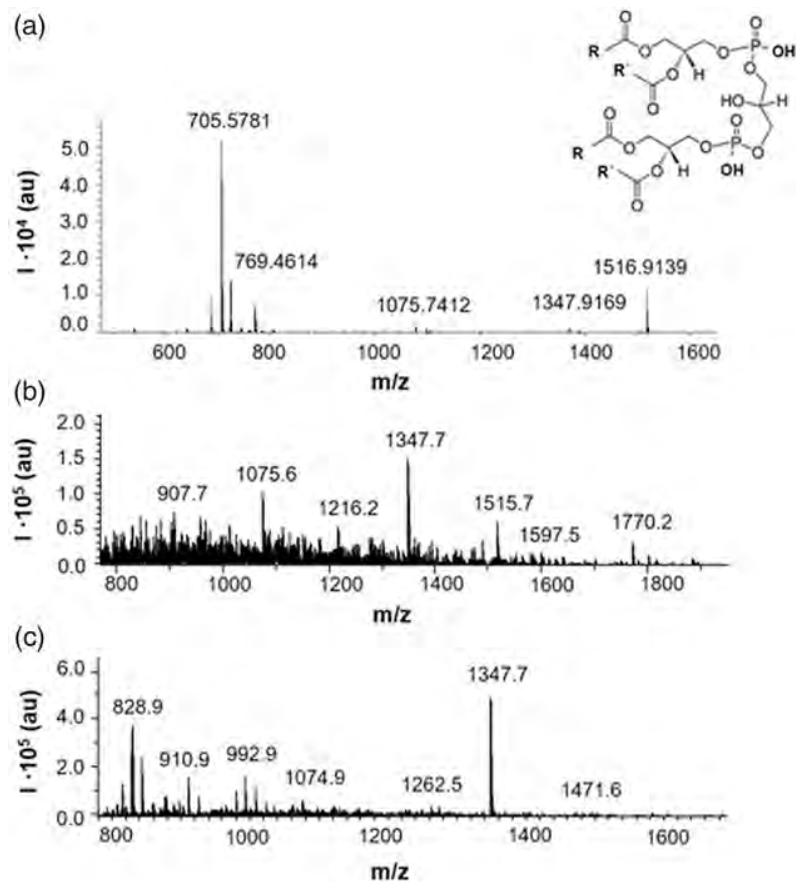

Figure 5. (a) $\mathrm{ESI}^{+}$-MS spectrum of a solution of $\mathrm{CL}$ standard in methanol. (b) HPTLC-ESI ${ }^{+}$-MS spectrum of $\mathrm{CL}$ standard. (c) HPTLC-ESI ${ }^{+}$-MS spectrum of $\mathrm{CL}$ zone (md $40 \mathrm{~mm}$ ) in the membrane extract from Rb. Blasticus. (See text for ion attribution).

response, and the aliphatic chain length does not modify it substantially.

When using LC-MS, the different composition of the gradient with retention time influences the ionization and 
changes the lipid responses. This does not occur in the case of using HPTLC because the solvent-developing gradient is evaporated before detection, and the interface eluting solvent has a constant composition ( $\mathrm{MeOH}$ in our case). Therefore, similar ionization efficiencies are obtained for the individual lipids of a class when using HPTLC-ESI-MS.

Ionization conditions obtained for each class of phospholipids using the above-mentioned standards were applied for the structural identification of the PL species in the bands separated by AMD from the membrane extracts. The migration distances of each zone of the plate transferred to the ion trap using the interface are detailed below and in the captions of Figures 6-8.

With regard to $R b$. blasticus, the HPTLC-ESI ${ }^{+}$-MS spectrum of PC species (band at $\mathrm{md} 12 \mathrm{~mm}$ ) was obtained as $[\mathrm{M}+\mathrm{Na}]^{+}$(Figure 6(a)). $\left[\mathrm{C}_{44} \mathrm{H}_{84} \mathrm{O}_{8} \mathrm{PN}+\mathrm{Na}\right]^{+}$at $\mathrm{m} / \mathrm{z} 808.4$ and $\left[\mathrm{C}_{42} \mathrm{H}_{82} \mathrm{O}_{8} \mathrm{PN}+\mathrm{Na}\right]^{+}$at $\mathrm{m} / \mathrm{z} 782.4$ were mostly found in this membrane, which correspond respectively to preponderant PC (36:2) and PC(34:1). These species are in agreement with a previous experiment carried out by LC-MS by Barret using a similar membrane extract [18]. Species at $\mathrm{m} / \mathrm{z}$ 890.4, 876.4 and 864.4 are artifacts.

Figure 6(b) shows PG molecular species found in $R b$. blasticus membrane extracts from the HPTLC-ESI ${ }^{-}$MS spectrum of the corresponding band at $\mathrm{md} 48 \mathrm{~mm}$, as $\left[\mathrm{C}_{42} \mathrm{H}_{78} \mathrm{O}_{10} \mathrm{P}\right]^{-}$at $\mathrm{m} / \mathrm{z}$ 773.2, $\left[\mathrm{C}_{40} \mathrm{H}_{76} \mathrm{O}_{10} \mathrm{P}\right]^{-}$at $\mathrm{m} / \mathrm{z}$ 747.1, and $\left[\mathrm{C}_{36} \mathrm{H}_{60} \mathrm{O}_{9} \mathrm{P}\right]^{-}$at $\mathrm{m} / \mathrm{z}$ 668.6. They respectively correspond to $\mathrm{PG}(36: 2)$, which was previously detected by LC-MS from a similar extract [18], PG(34:1), and a probable lysoPG structure. Other ions in this spectrum (at $\mathrm{m} / \mathrm{z} 702.5$, 831.5 and 868.5) were detected at low intensities and probably corresponding to other unidentified PG species. Ion at 714.6 may correspond to an artifact.

PE species in the band at $\mathrm{md} 30 \mathrm{~mm}$ of $R b$. blasticus membrane extract were also detected at low intensities (not shown). These signals were of the same order of magnitude
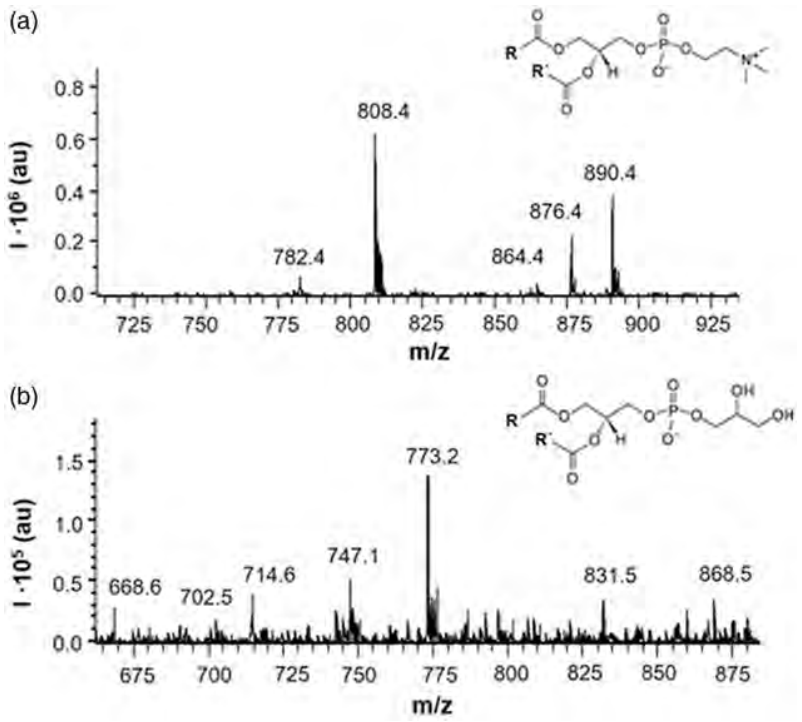

Figure 6. Membrane extract from Rb. Blasticus: (a) HPTLC-ESI ${ }^{+}$-MS spectrum of PC zone (md $12 \mathrm{~mm})$. * Ion at $\mathrm{m} / \mathrm{z}$ 864.4: $[\mathrm{PC}(34: 1)+\mathrm{Na}]^{+}(\mathrm{CH} 3-\mathrm{COONa})$; ion at $\mathrm{m} / \mathrm{z}$ 876.4: $\quad[\mathrm{PC}(36: 2)+\mathrm{Na}]^{+} \quad(\mathrm{HCOONa}) ;$ and ion at $\mathrm{m} / \mathrm{z}$ 890.4: $[\mathrm{PC}(36: 2)+\mathrm{Na}]^{+}(\mathrm{CH} 3-\mathrm{COONa})$. (b) HPTLC-ESI $-\mathrm{MS}$ spectrum of PG zone (md $48 \mathrm{~mm})$. *Ion at m/z 714.6: NaAcO cluster. (See text for ion attribution). as those of background sodium acetate clusters. In general, negative ionization of PE was difficult. The ionization efficiency of PE species as protonated and/or sodiated adducts is lower than that of PC species, since the quaternary amine of PC with positive charge is much more stable than the primary amine of $\mathrm{PE}[1]$.

The search of CL species in $R b$. blasticus membrane extract by LC-MS failed in the above-mentioned previous work by Barret [18]. In our case, ESI ${ }^{-}$did not work for an efficient ionization of the CL band at $\mathrm{md} 40 \mathrm{~mm}$. However, we obtained a good spectrum using $\mathrm{ESI}^{+}$(see Figure 5(c)). An intense ion at m/z 1347.7 was obtained. As ions at this same mass to charge value also appear in CL standard spectrum (Figure 5(b)), both in solution and from the plate, one could think that this is an indication of the presence of a $\mathrm{CL}(60: 8)$ species in this extract. However, this identification is not unambiguous. The MS/MS spectrum obtained from this precursor ion provided a product ion at $\mathrm{m} / \mathrm{z} 997.7$ which could not be identified as a fragment of cardiolipin by any of the fragmentation patterns proposed classically. In the other membrane extracts studied in this work, no CL species were found either.

Concerning membrane extract of $R$. rubrum, two PE species were identified from the band at $\mathrm{md} 30 \mathrm{~mm}$. Thus, $\left[\mathrm{C}_{37} \mathrm{H}_{72} \mathrm{O}_{8} \mathrm{PN}-\mathrm{H}\right]^{-}$at $\mathrm{m} / \mathrm{z} 688.2$ and $\left[\mathrm{C}_{41} \mathrm{H}_{78} \mathrm{O}_{8} \mathrm{PN}-\mathrm{H}\right]^{-}$at $\mathrm{m} /$ z 742.2 correspond to $\mathrm{PE}(32: 1)$ and $\mathrm{PE}(36: 2)$, respectively (Figure $7(\mathrm{a})$ ). Other ions at $\mathrm{m} / \mathrm{z} 714.3,796.5$ and 878.6 were considered artifacts. As an example of unequivocal identification of PE species, it was possible to isolate and fragment the precursor ion at $\mathrm{m} / \mathrm{z} 742.2$ to obtain an ion product from the MS/MS spectrum at $\mathrm{m} / \mathrm{z} 682.2\left[\mathrm{C}_{39} \mathrm{H}_{71} \mathrm{O}_{7} \mathrm{P}-\mathrm{H}\right]^{-}$. This involves a loss of an ethanolamine $\left[-\mathrm{OCH}_{2} \mathrm{CH}_{2} \mathrm{NH}_{3}\right]$ group (Figure $7(\mathrm{~b})$ ) by fragmentation of the ion precursor, which can be therefore identified as PE (36:2).

Several PC species, as $[\mathrm{M}+\mathrm{Na}]^{+}$, were also found at low intensity signals from this membrane extract (not shown). The low concentration and the absence of preponderant PC species in $R d$. rubrum extracts were evidenced by Russell
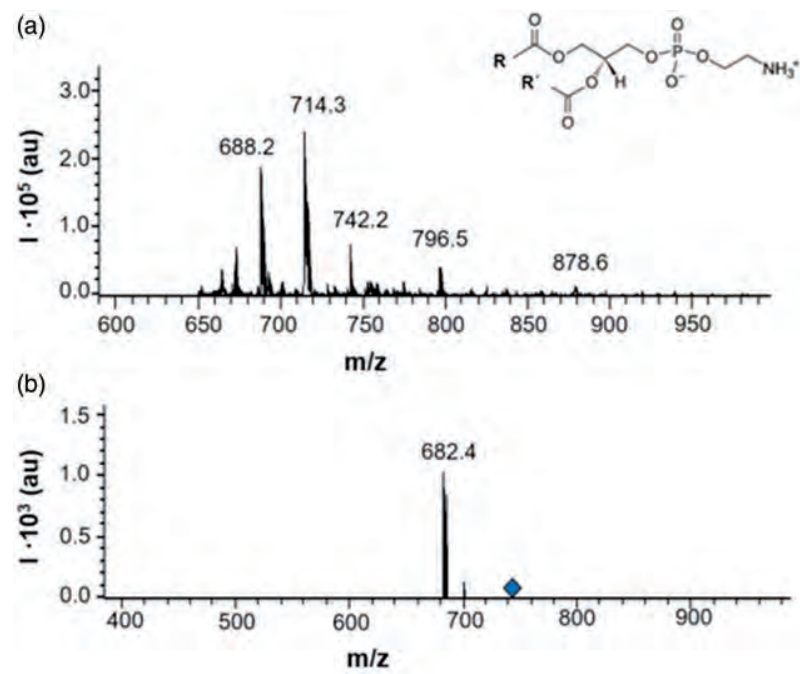

Figure 7. Membrane extract from Rd. rubrum: (a) HPTLC-ESI-MS spectrum of PE zone (md $30 \mathrm{~mm}$ ). *lons at $\mathrm{m} / \mathrm{z} 714.3,796.5$; and 876.6: NaAcO clusters. (b) HPTLC-ESI-MS/MS spectrum of the precursor ion at $\mathrm{m} / \mathrm{z} 742.2$, with product ion at $\mathrm{m} / \mathrm{z}$ 682.4. (See text for ion attribution). 
and Harwood [19] and references therein. Likewise, PG species were not found in this membrane extract.

\subsection{Membrane extract and purified photosynthetic complex (RC-LH1-pufX) from Rhodobaca (Rbc.) bogoriensis}

HPTLC-ESI ${ }^{+}$-MS spectra, both of the membrane extract as of the purified complex from Rbc. bogoriensis, show clear, intense and defined PC species (Figure 8). The preponderant ion in the membrane extract, at $\mathrm{m} / \mathrm{z}$ 808.6, $\left[\mathrm{C}_{44} \mathrm{H}_{84} \mathrm{O}_{8} \mathrm{PN}+\mathrm{Na}\right]^{+}$, can be attributed to PC (36:2). Other $\mathrm{PC}$ species were found in lower concentration, such as ions at $\mathrm{m} / \mathrm{z} \quad 782.6 \quad\left(\left[\mathrm{C}_{42} \mathrm{H}_{82} \mathrm{O}_{8} \mathrm{PN}+\mathrm{Na}\right]^{+}\right)$and 822.7 $\left(\left[\mathrm{C}_{45} \mathrm{H}_{86} \mathrm{O}_{8} \mathrm{PN}+\mathrm{Na}\right]^{+}\right)$, which correspond to $\mathrm{PC}(34: 1)$ and PC (37:2), respectively.

The purified complex from this bacterium shows an HPTLC-ESI $^{+}$-MS spectrum (Figure 8(b)) with ions corresponding to $\mathrm{PC}(37: 2)$ at $\mathrm{m} / \mathrm{z} 822.6\left[\mathrm{C}_{45} \mathrm{H}_{86} \mathrm{O}_{8} \mathrm{PN}+\mathrm{Na}\right]^{+}$; $\mathrm{PC}(36: 2)$ at $\mathrm{m} / \mathrm{z} 808.6\left[\mathrm{C}_{44} \mathrm{H}_{84} \mathrm{O}_{8} \mathrm{PN}+\mathrm{Na}\right]^{+}$; $\mathrm{PC}(39: 2)$ at $\mathrm{m} / \mathrm{z} 850.5\left[\mathrm{C}_{47} \mathrm{H}_{90} \mathrm{O}_{8} \mathrm{PN}+\mathrm{Na}\right]^{+} ; \mathrm{PC}(28: 0)$ at $\mathrm{m} / \mathrm{z} 700.5$ $\left[\mathrm{C}_{36} \mathrm{H}_{72} \mathrm{O}_{8} \mathrm{PN}+\mathrm{Na}\right]^{+} ;$and $\mathrm{PC}(34: 1)$ at $\mathrm{m} / \mathrm{z} \quad 782$ $\left[\mathrm{C}_{42} \mathrm{H}_{82} \mathrm{O}_{8} \mathrm{PN}+\mathrm{Na}\right]^{+}$.

PG species showed a good ionization in ESI'. The purified complex shows strong signals due to PG ions, the most prominent being PG (36:2) at $\mathrm{m} / \mathrm{z} 773.3\left[\mathrm{C}_{42} \mathrm{H}_{78} \mathrm{O}_{10} \mathrm{P}\right]^{-}$ (Figure $8(\mathrm{c})$ ). Other species with lower intensity were PG (34:4) at $\mathrm{m} / \mathrm{z} 742.3\left[\mathrm{C}_{40} \mathrm{H}_{70} \mathrm{O}_{10} \mathrm{P}\right]^{-}$, and PG (33:4) at $\mathrm{m} / \mathrm{z}$ $727.3\left[\mathrm{C}_{39} \mathrm{H}_{68} \mathrm{O}_{10} \mathrm{P}\right]^{-}$.

On the other hand, no PE species were found in the membrane extracts or in the purified complex.

A higher number of species is detected in the complex than in the extract. In the case of PC, all the species of the
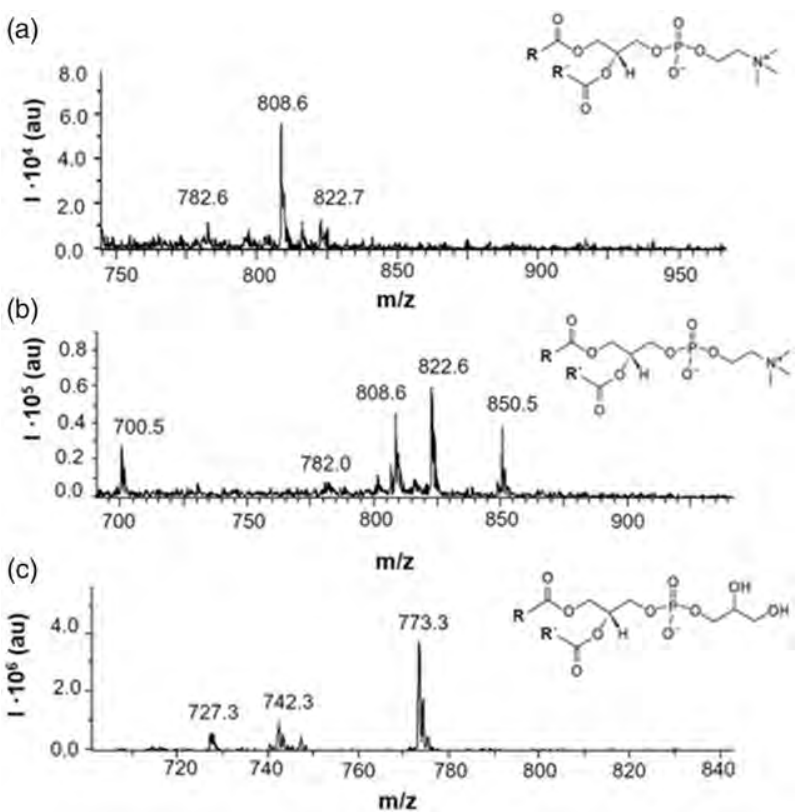

Figure 8. (a) $\mathrm{HPTLC}^{-E S I}{ }^{+}$-MS spectrum of $\mathrm{PC}$ zone ( $\mathrm{md} 12 \mathrm{~mm}$ ) of membrane extract from Rbc. bogoriensis. (b) HPTLC-ESI ${ }^{+}$-MS spectrum of PC zone (md $12 \mathrm{~mm}$ ) of the purified RC-LH1-PufX complex from Rbc. bogoriensis. (C) HPTLCESI-MS spectrum of PG zone ( $\mathrm{md} 48 \mathrm{~mm}$ ) of the purified RC-LH1-PufX complex from $R b c$. bogoriensis. (See text for ion attribution). extract are in the complex, which presents some species more. In the case of PG, no species are observed in the extract but in the complex. All this is probably due to the fact that the lipid species are more concentrated in the purified complex than in the membrane extract. It is not surprising given that PG is crucial for the stability and functionality of the PSII supercomplex, the counterpart of RCLH1-pufX in the higher plants [20,21].

Some detected chains of fatty acids show an odd number of carbon atoms. This fact was already described in the case of other non-sulfurous purple bacteria, such as Rhodopseudomonas acidophila and Rhodobacter (R.) sphaeroides [22-26].

The PL species found in the studied bacterial membrane samples are summarized in Table 2.

\section{Conclusion}

The ease of use of HPTLC coupled to Electrospray mass spectrometry (ESI-MS) using an elution-based interface, its rapidity and selective access to specific zones of interest on the plate were useful for obtaining rapid relevant information about the identity of several phospholipid species associated to MP in bacterial membrane extracts. In particular, five PC and three PG species were identified as directly associated to the RC-LH1-pufX photosynthetic complex from Rhodobaca (Rbc.) bogoriensis purified under our conditions. As far as the authors know, this analytical problem was not addressed previously using HPTLC-MS.

ESI-MS and MS/MS spectra from the bands separated on the plate were obtained, in a quick, reliable and simple manner. In general, spectra showed good intensity and quality.

Both the spectra and the PL fragmentation patterns were similar to those described in solution for standards and samples, using both ionization modes.

When using $\mathrm{ESI}^{+}$under the studied conditions, the stability of the sodium adducts was so high that it allowed ion fragmentations to be achieved by low-energy collisioninduced dissociation at ion-trap mild conditions, resulting in

Table 2. Molecular species of phospholipids found in bacterial membrane samples by HPTLC-MS.

\begin{tabular}{|c|c|c|c|c|c|}
\hline & & $\mathrm{m} / \mathrm{z}$ & $\begin{array}{c}\text { Molecular } \\
\text { species }\end{array}$ & $\begin{array}{c}\text { Ionization } \\
\text { forms }\end{array}$ & $\begin{array}{l}\text { Molecular } \\
\text { formula }\end{array}$ \\
\hline \multirow[t]{4}{*}{ Rb. Blasticus } & PC & $\begin{array}{l}808.4 \\
782.4\end{array}$ & $\begin{array}{l}(36: 2) \\
(34: 1)\end{array}$ & {$[\mathrm{M}+\mathrm{Na}]^{+}$} & $\begin{array}{l}{\left[\mathrm{C}_{44} \mathrm{H}_{84} \mathrm{O}_{8} \mathrm{PN}+\mathrm{Na}\right]^{+}} \\
{\left[\mathrm{C}_{44} \mathrm{H}_{82} \mathrm{O}_{8} \mathrm{PN}+\mathrm{Na}^{+}\right.}\end{array}$ \\
\hline & PG & 773.2 & $(36: 2)$ & {$[\mathrm{M}]^{-}$} & ${ }^{\left[C_{42} \mathrm{H}_{78} \mathrm{O}_{10} \mathrm{P}\right]^{-}}$ \\
\hline & & 747.1 & $(34: 1)$ & & {$\left[\mathrm{C}_{40} \mathrm{H}_{76} \mathrm{O}_{10} \mathrm{P}\right]^{-}$} \\
\hline & & 686.6 & $\begin{array}{l}\text { Lyso-PG } \\
(30: 6)\end{array}$ & & {$\left[\mathrm{C}_{36} \mathrm{H}_{60} \mathrm{O}_{9} \mathrm{P}\right]^{-}$} \\
\hline \multirow[t]{2}{*}{ Rb. Rubrum } & PE & 742.2 & $(36: 2)$ & {$[\mathrm{M}-\mathrm{H}]^{-}$} & {$\left[\mathrm{C}_{41} \mathrm{H}_{78} \mathrm{O}_{8} \mathrm{PN}-\mathrm{H}\right]^{-}$} \\
\hline & & 688.2 & $(36: 1)$ & & {$\left[\mathrm{C}_{37} \mathrm{H}_{72} \mathrm{O}_{8} \mathrm{PN}-\mathrm{H}\right]^{-}$} \\
\hline \multirow{3}{*}{ Rb. Bogoriensis } & PC & 808.6 & $(36: 2)$ & {$[\mathrm{M}+\mathrm{Na}]^{+}$} & {$\left[\mathrm{C}_{44} \mathrm{H}_{84} \mathrm{O}_{8} \mathrm{PN}+\mathrm{Na}\right]^{+}$} \\
\hline & & 782.6 & $(34: 1)$ & & {$\left[\mathrm{C}_{42} \mathrm{H}_{82} \mathrm{O}_{8} \mathrm{PN}+\mathrm{Na}\right]^{+}$} \\
\hline & & 822.7 & $(37: 2)$ & & {$\left[\mathrm{C}_{45} \mathrm{H}_{86} \mathrm{O}_{8} \mathrm{PN}+\mathrm{Na}\right]^{+}$} \\
\hline \multirow[t]{8}{*}{ RC-LH1-PufX complex } & PC & 822.6 & $(37: 2)$ & {$[\mathrm{M}+\mathrm{Na}]^{+}$} & {$\left[\mathrm{C}_{45} \mathrm{H}_{86} \mathrm{O}_{8} \mathrm{PN}+\mathrm{Na}\right]^{+}$} \\
\hline & & 808.6 & $(36: 2)$ & & {$\left[\mathrm{C}_{44} \mathrm{H}_{84} \mathrm{O}_{8} \mathrm{PN}+\mathrm{Na}\right]^{+}$} \\
\hline & & 850.5 & $(39: 2)$ & & {$\left[\mathrm{C}_{47} \mathrm{H}_{90} \mathrm{O}_{8} \mathrm{PN}+\mathrm{Na}\right.$} \\
\hline & & 700.5 & $(28: 0)$ & & {$\left[\mathrm{C}_{36} \mathrm{H}_{72} \mathrm{O}_{8} \mathrm{PN}+\mathrm{Na}\right.$} \\
\hline & & 782.0 & $(34: 1)$ & & {$\left[\mathrm{C}_{42} \mathrm{H}_{82} \mathrm{O}_{8} \mathrm{PN}+\mathrm{Na}\right]^{+}$} \\
\hline & PG & 773.3 & $(36: 2)$ & {$[\mathrm{M}]^{-}$} & {$\left[\mathrm{C}_{42} \mathrm{H}_{78} \mathrm{O}_{10} \mathrm{P}\right]^{-}$} \\
\hline & & 742.3 & $(34: 4)$ & & {$\left[\mathrm{C}_{40} \mathrm{H}_{70} \mathrm{O}_{10} \mathrm{P}\right]^{-}$} \\
\hline & & 727.3 & $(33: 4)$ & & {$\left[\mathrm{C}_{39} \mathrm{H}_{68} \mathrm{O}_{10} \mathrm{P}\right]^{-}$} \\
\hline
\end{tabular}


cleavage of the most labile bonds when reaching certain threshold energy.

\section{Acknowledgments}

Authors thank Melanie Broszat and Eliezer Ceniviva (CAMAG) for videodensitometry experiments.

\section{Funding}

This work was supported by the DGA-ESF under project E25 17R.

\section{ORCID}

Vicente L. Cebolla (D) http://orcid.org/0000-0002-9786-9217

\section{References}

[1] Han, X. Lipidomics: Comprehensive Mass Spectrometry of Lipids, Wiley \& Sons, Inc.: New Jersey, 2016.

[2] Morlock, G. E.; Schwack, W. Coupling of Planar Chromatography to Mass Spectrometry. TrAC. 2010, 29, 1157-1171. DOI: 10.1016/j.trac.2010.07.010.

[3] Cebolla, V. L.; Membrado, L.; Jarne, C.; Garriga, G. High-performance thin-layer chromatography. In Analytical Separation Science, Vol.4; Anderson, J.; Berthod, A.; Pino Estévez, V; Stalcup, A. Eds.; Wiley-VCH: Berlin, 2001, pp 1093-1141.

[4] Jarne, C.; Savirón, M.; Lapieza, M. P.; Membrado, L.; Orduna, J.; Galbán, J.; Garriga, R.; Morlock, G.; Cebolla, V. L. HighPerformance Thin-Layer Chromatography Coupled with Electrospray Ionization Tandem Mass Spectrometry for Identifying Neutral Lipids and Sphingolipids in Complex Samples. J. AOAC Int. 2018, 101, 1993-2000. DOI: 10.5740/jaoacint.17-0329.

[5] Luckey, M. Membrane Structural Biology. With Biochemical and Biophysical Foundations. Second edition, Cambridge University Press, Cambridge, 2014, ch. 3.

[6] Barret, L. A.; Barrot-Ivolot, C.; Raynal, S.; Jungas, C.; Polidori, A.; Bonnete, F. Influence of Hydrophobic Micelle Structure on Crystallization of the Photosynthetic RC-LH1-PufX Complex from Rhodobacter blasticus. J. Phys. Chem. B. 2013, 117, 8770-8781. DOI: 10.1021/jp403483q.

[7] Arnaud, C. H. Lipids Affect the Function of Membrane Proteins. Chemical \& Engineering News 2017, 95, 18-20. https://cen.acs. org/articles/95/i9/Lipids-affect-function-membrane-proteins.html

[8] Deisenhofer, J.; Michel, H. Nobel Lecture. The Photosynthetic Reaction Centre from the Purple Bacterium Rhodopseudomonas viridis. Embo Journal 1989, 8, 2149-2170. DOI: 10.1002/j.1460-2075.1989.tb08338.x.

[9] Jungas, C.; Ranck, J. L.; Rigaud, J. L.; Joliot, P.; Vermeglio, A. Supramolecular Organization of the Photosynthetic Apparatus of Rhodobacter sphaeroides. Embo Journal 1999, 18, 534-542. DOI: $10.1093 /$ emboj/18.3.534.

[10] Comayras, R.; Jungas, D.; Lavergne, J. Functional Consequences of the Organization of the Photosynthetic Apparatus in Rhodobacter sphaeroides I. Quinone Domains and Excitation Transfer in Chromatophores and Reaction Center-antenna Complexes. J. Biol. Chem. 2005, 280, 11203-11213. DOI: 10.1074/jbc.M412088200.

[11] Semchonok, D. A.; Chauvin, J. P.; Frese, R. N.; Jungas, C.; Boekema, E. J. Structure of the Dimeric RC-LH1-PufX Complex from Rhodobaca bogoriensis Investigated by Electron Microscopy. Phil. Trans. R. Soc. B. 2012, 367, 3412-3419. DOI: 10.1098/rstb.2012.0063.

[12] Zhou, S. L.; Hamburger, M. Formation of Sodium Cluster Ions in Electrospray Mass Spectrometry. Rapid Commun. Mass
Spectrom. 1996, 10, 797-800. DOI: $10.1002 /(\mathrm{SICI}) 1097-$ 0231(199605)10:7\%3C797::AID-RCM550\%3E3.0.CO;2-7.

[13] Keller, B. O.; Sui, J.; Young, A. B.; Whittal, R. M. Interferences and Contaminants Encountered in Modern Mass Spectrometry. Anal. Chim. Acta. 2008, 627, 71-81. DOI: 10.1016/j.aca.2008.04.043.

[14] Hsu, F. F.; Turk, J.; Rhoades, E. R.; Russell, D. G.; Shi, Y. X.; E.A. Groisman, E. A. Structural Characterization of Cardiolipin by Tandem Quadrupole and Multiple-stage Quadrupole Ion-trap Mass Spectrometry with Electrospray Ionization. J. Am. Soc. Mass Spectrom. 2005, 16, 491-504. DOI: 10.1016/j.jasms.2004.12.015.

[15] Hsu, F. F.; Turk, J. Characterization of Cardiolipin as the Sodiated Ions by Positive-ion Electrospray Ionization with Multiple Stage Quadrupole Ion-trap Mass Spectrometry. J. Am. Soc. Mass Spectrom. 2006, 17, 1146-1157. DOI: 10.1016/ j.jasms.2006.04.024.

[16] Alves Maciel, M. E. Identification of oxidation products of cardiolipin using Mass Spectrometry. PhD Thesis, University of Aveiro, Portugal, 2010.

[17] Maciel, E.; Domingues, P.; Marques, D.; Simões, C.; Reis, A.; Oliveira, M. M.; Videira, R. A.; Peixoto, F.; Domingues, M. R. M. Cardiolipin and Oxidative Stress: Identification of New Short Chain Oxidation Products of Cardiolipin in in Vitro Analysis and in Nephrotoxic Drug-induced Disturbances in Rat Kidney Tissue. Int. J. Mass Spectrom. 2011, 301, 62-73. DOI: 10.1016/j.ijms.2010.06.036.

[18] Barret, L. A. Influence des tensioactifs dans la cristallisation du complexe photosynthétique RC-LH1-pufX de Rhodobacter blasticus. France: PhD Thesis, Université d'Avignon et des Pays du Vaucluse, 2013.

[19] Russell, N. J.; Harwood, J. L. Changes in the Acyl Lipid Composition of Photosynthetic Bacteria Grown under Photosynthetic and Non-photosynthetic Conditions. Biochem. J. 1979, 181, 339-345. DOI: 10.1042/bj1810339.

[20] Sato, N.; Hagio, M.; Wada, H.; Tsuzuki, M. Requirement of Phosphatidylglycerol for Photosynthetic Function in Thylakoid Membranes. Proc. Natl. Acad. Sci. U S A 2000, 97, 10655-10660. DOI: 10.1073/pnas.97.19.10655.

[21] Hagio, M.; Gombos, Z.; Várkonyi, Z.; Masamoto, K.; Sato, N.; Tsuzuki, M.; Wada, H. Direct Evidence for Requirement of Phosphatidylglycerol in Photosystem II of Photosynthesis. Plant Physiol. 2000, 124, 795-804. DOI: 10.1104/pp.124.2.795.

[22] Russell, N. J.; Coleman, J. K.; Howard, T. D.; Johnston, E.; Cogdell, R. J. Rhodopseudomonas acidophila Strain 10050 Contains Photosynthetic LH2 Antenna Complexes That Are Not Enriched with Phosphatidylglycerol, and the Phospholipids Have a Fatty Acyl Composition That Is Unusual for Purple Non-sulfur Bacteria. Biochim. Biophys. Acta-Bioenergetics. 2002, 1556, 247-253. DOI: 10.1016/S0005-2728(02)00369-9.

[23] Granafei, S.; Losito, I.; Trotta, M.; Agostiano, A.; Palmisano, F.; Cataldi, T. R. I. Unveiling the Compositional Variety of Cardiolipins in Rhodobacter sphaeroides by Liquid Chromatography with Electrospray Ionization and Multistage Collision-induced Dissociation Mass Spectrometry. Anal. Bioanal. Chem. 2017, 409, 5007-5018. DOI: 10.1007/s00216-017-0444-1.

[24] Granafei, S.; Losito, I.; Trotta, M.; Italiano, F.; de Leo, V.; Agostiano, A.; Palmisano, F.; Cataldi, T. R. I. Profiling of Ornithine Lipids in Bacterial Extracts of Rhodobacter sphaeroides by Reversed-phase Liquid Chromatography with Electrospray Ionization and Multistage Mass Spectrometry (RPLC-ESI-MS ${ }^{\mathrm{n}}$ ). Anal. Chim. Acta. 2016, 903, 110-120. DOI: 10.1016/j.aca.2015.11.020.

[25] Granafei, S.; Losito, I.; Salivo, S.; Tranchida, P. Q.; Mondello, L.; Palmisano, F.; Cataldi, T. R. I. Occurrence of Oleic and 18: Methyl-branched Acyl Chains in Lipids of Rhodobacter sphaeroides 2.4.1. Anal. Chim. Acta 2015, 885, 191-198. DOI: 10.1016/j.aca.2015.05.028

[26] Imhoff, J. F.; Bias-Imhoff, U. Lipids, Quinones and Fatty Acids of Anoxygenic Phototrophic Bacteria. In Anoxygenic Photosynthetic Bacteria. Blankenship, R. E.; Madigan, M. T.; Bauer C. E. Eds.; Kluwer Academic Publishing: Dordrecht, 1995; pp. 179-205. 